
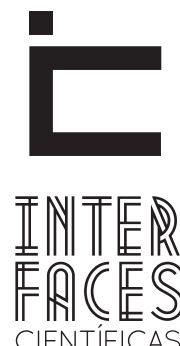

HUMANAS E SOCIAIS

\title{
EDUCAÇ̃̃O NUTRICIONAL: DO JECA TATU À OBESIDADE
}

Hugo José Xavier Santos ${ }^{1}$
Lívia de Melo Barros
Bettina Steren dos Santos ${ }^{2}$

\section{RESUMO}

0 artigo objetiva traçar um panorama sobre a educação nutricional no Brasil desde o seu surgimento até a atualidade, por meio de pesquisas bibliográficas dos últimos anos, discutida no campo da história, da cultura, da nutrição e da alimentação em nosso país, a fim de destacar as bases das políticas públicas, muito bem salientada por Monteiro Lobato e Josué de Castro em suas obras literárias. Este contexto indica que a finalidade das propostas educativas em alimentação e nutrição é mais subsidiar os indivíduos com informações adequadas, corretas e consistentes sobre alimentos, alimentação e prevenção de problemas nutricionais e menos os auxiliar na tomada de decisões. As mudanças sociais, culturais e econômicas refletem o modo de vida da população. No início do século XX, os males que afligiam a população eram as epidemias causadas por doenças transmissíveis e algumas ainda não foram debeladas, como a dengue. Já no século XXI, ocorreram transformações no perfil epidemiológico e, hoje, disseminam-se as doenças crônicas não transmissíveis. Atualmente, a importância desta modalidade de educação na vida dos cidadãos e sua comunidade residem na conscientização, por meio de estratégias de ensino, no respeito e na valorização dos aspectos culturais, econômicos, psicológicos, ambientais e sociais, alicerçados na educação. Mensurar constantemente o impacto que os hábitos de alimentação inadequados podem causar a uma população, é resultante de uma melhora da qualidade de vida do indivíduo e sua comunidade.

\section{PALAVRAS-CHAVES}

Educação. Educação Nutricional. Alimentação. 


\section{ABSTRACT}

The article aims to give an overview on nutrition education in Brazil from its inception to the present, through literature searches in recent years, discussed in the field of history, culture, nutrition and food in our country, in order to highlight the basis of public policy, very well highlighted by Monteiro Lobato and Josué de Castro in his literary works. This context indicates that the purpose of educational proposals in food and nutrition is more support individuals with adequate, correct and consistent information on food, nutrition and prevention of nutritional problems and less help them in decision making. Social, cultural and economic changes reflect the way of life of the population. In the early twentieth century, the evils afflicting the population were epidemics caused by communicable diseases and some have not yet been addressed, such as dengue. Already in the twenty-first century, there

\section{RESUMEN}

El artículo pretende dar una visión general sobre la educación nutricional en Brasil desde sus inicios hasta la actualidad, a través de búsquedas en las literaturas en los últimos años, discutida en el campo de la historia, la cultura, la nutrición y la alimentación en nuestro país, con el fin de señalar las bases de las políticas públicas, así como destacadas por Monteiro Lobato y Josué de Castro en sus obras literarias. Este contexto indica que el propósito de las propuestas educativas en alimentación y nutrición es más ayudar a los individuos con informaciones adecuadas, correctas y coherentes sobre los alimentos, la nutrición y la prevención de los problemas nutricionales y menos ayudarlos en la toma de decisiones. Los cambios sociales, culturales y económicos reflejan el modo de vida de la población. A principios del siglo XX, los males que afligían la población fueron las epidemias causadas por enfermedades transmisibles y algunas were changes in the epidemiological profile and today spread to non-communicable chronic diseases. Currently, the importance of this type of education in the lives of citizens and their community residing in awareness through teaching strategies, respect and appreciation of cultural, economic, psychological, environmental and social, grounded in education. Constantly measure the impact that inadequate eating habits can cause a population, it is the result of an improvement in the quality of life of individuals and their community.

\section{KEYWORDS}

Education. Nutrition Education. Food.

todavía existentes, como la dengue. Ya en el siglo XXI, ocurrieron cambios en el perfil de epidemias y, hoy, se diseminan enfermedades crónicas no transmisibles. Actualmente, la importancia de esta modalidad de educación en la vida de los ciudadanos y su comunidad están en el reconocimiento, a través de estrategias de enseñanza, en el respeto y la valoración de los aspectos culturales, económicos, psicológicos, ambientales y sociales, basados en la educación. Medir constantemente el impacto que los hábitos alimenticios inadecuados pueden causar a una población es el resultado de una mejora en la calidad de vida de los individuos y su comunidad.

\section{PALABRAS CLAVE}

Educación. Educación nutricional. Alimentación. 


\section{DE MONTEIRO LOBATO A JOSUÉ DE CASTRO}

Em seu sentido mais amplo, segundo a Organização Mundial da Saúde - OMS (1986), a saúde é o resultante das condições de alimentação, habitação, educação, renda, meio ambiente, trabalho, transporte, emprego, lazer liberdade, acesso à posse da terra e a serviços nessa área. "É assim, antes de tudo, o resultado das formas de organização social da produção, as quais podem gerar grandes desigualdades nos níveis de vida" (OMS, 1986).

A política de saúde do trabalhador no Brasil começou a ser planejada após a promulgação da Constituição Federal de 1988. No artigo 196, consta que:

A saúde é um direito de todos, e dever do Estado garantido mediante políticas sociais e econômicas que visem à redução do risco da doença e de outros agravos e ao acesso universal e igualitário às ações e serviços para sua promoção, proteção e recuperação. (BRASIL, 2007, on-line).

Os primeiros ares de república no Brasil trouxeram um ambiente que oscilava em torno da euforia desmedida de alguns setores da sociedade. Em um painel social mais grave, os intelectuais brasileiros adotavam duas posturas assimétricas: de um lado, aqueles que pregavam o progresso, a abolição, a república e a democracia como a panaceia do país e, para tanto, acreditavam que a saída era atualizar a sociedade brasileira com o modo de vida típico europeu, visto que havia a importação de modelos artísticos e culturais, principalmente franceses (MACHADO, 1973).

No outro polo, havia aqueles intelectuais que, influenciados pelo cientificismo - também importado da Europa -, adotavam uma postura diferenciada e preconizavam o mergulho na realidade brasileira para melhor conhecê-la, o estudo aprofundado de nossa história, nossos processos, características e problemas. Estes últimos estavam preocupados em construir um saber próprio sobre o Brasil e, quiçá, transformar a realidade (PASSINI, 2002).
A literatura pré-modernista, ainda segundo Passini (2002), em certo sentido, modificou e aproximou as relações entre escritor e público ao se tornar porta-voz dos anseios, desejos e necessidades deste último. A aproximação, também, reverbera nos procedimentos estilísticos: filiação com a oralidade, incorporação de temas folclóricos, mergulho no regionalismo. As transformações formais são acompanhadas de mudanças no conteúdo das obras, com enfoque para temas populares e cotidianos e que retratavam, em certa medida, a condição e o imaginário do público leitor.

Nesse aspecto, insere-se Monteiro Lobato, com suas ideias e obras sobre e para o Brasil. 0 autor e outros intelectuais da época, usavam seus trabalhos para denunciar as mazelas da República, principalmente as questões sociais - muito bem explicitadas em seu personagem mais famoso, o Jeca Tatu (1940), por exemplo. Este representa a imagem do homem do campo, franzino, amarelo, preguiçoso, que vive de cócoras, em péssimas condições de higiene e de saúde. Símbolo do descuido do governo para a população, principalmente do campo.

Assim, Monteiro Lobato, apesar de retratar a imagem negativa do homem do campo, curvou-se à realidade, e verificou que "os caipiras eram barrigudos e preguiçosos por motivo de doenças". Seres que tinham suas entranhas corroídas por um parasito (ancylostomaduodenale) adquirido por falta de higiene e saneamento básico.

Tal qual Monteiro Lobato, o médico, sociólogo, professor, geógrafo e político Josué de Castro estudou as causas da miséria em nosso país e no mundo e afirmou que ambas eram frutos de uma sociedade injusta. Esta afirmação foi considerada no ano de 1946, como uma entre várias ideias revolucionárias, nas quais se destacam os primeiros conceitos sobre 0 desenvolvimento sustentável. Em suas obras, princi- 
palmente Geografia da fome (1946), traça não só um panorama do Brasil a partir de suas características alimentares, como também deixa evidente a trágica situação da fome no país, atribuída aos sistemas sociais e econômicos que poderiam ser transformados para o beneficio da população e não aos fenômenos naturais como afirmavam os governantes.

Nesse mapeamento de Josué de Castro, destaca-se a figura do nordestino, no qual, semelhante ao Jeca Tatu, a fome se manifesta por doenças que enfraquecem o organismo, dentre elas, o beribéri, a pelagra, o raquitismo, de modo mais sutil, por déficit de proteínas, vitaminas e minerais, que se revelam por meio de lassidão, irritabilidade, nervosismo ou falta de apetite. 0 autor destaca ainda o desequilíbrio causado pelo modelo de crescimento industrial exclusivo sem alterações na estrutura arcaica da agricultura, e pelo tipo de economia voltado para o interesse internacional.

A preocupação com um país igualitário é evidente na obra dos dois autores, visto que a enfatizam em algumas representações dicotômicas: doenças x saúde; atraso x desenvolvimento; ignorância x educação; raiz brasileira $x$ estrangeirismo; preguiça $x$ trabalho. Com essas obras e seus pensamentos, os dois autores demonstraram que era possível construir uma ciência que teria como objeto de estudo problemas específicos de países subdesenvolvidos e que fosse capaz de explicar suas respectivas situações, sem recorrer aos mitos de inferioridade racial ou de determinismo geográfico. Além disso, destacaram-se a necessidade de fortalecer o mercado interno e a transformação da estrutura agrária, para aumentar a oferta de alimentos.

Nesse sentido, estratégias de formulação e implementação de uma política nacional de nutrição, remontam à década de 1940, quando, desde então, vêm sendo estabelecidos alguns eixos centrais de intervenção para o setor como: a Suplementação Alimentar; a Racionalização do Processo de Produção e Comercialização de Alimentos Básicos e a Educação Alimentar. Dentre os grupos prioritariamente atendidos pelos pro- gramas de nutrição, ao longo das seis últimas décadas, destacam-se os trabalhadores. 0 objetivo das intervenções destinadas a este grupo refere-se ao planejamento nutricional institucionalizado, por meio da oferta de refeições, visando atender aos desgastes do processo de trabalho e simultaneamente, formar hábitos alimentares saudáveis (PINHEIRO ET AL., 2004).

Nessa mesma década, o livro Geografia da Fome (1946), de Josué de Castro, é lançado e apresenta um dos mais profundos estudos brasileiros sobre a insegurança alimentar presente no Brasil, sobretudo nas regiões Norte e Nordeste. Aponta, também, que a falta de nutrientes, na comida cotidiana de tais povos, se dá por características climáticas, culturais e do solo, próprias de cada localidade, além do motivo principal: a concentração de terra na mão de poucas pessoas.

O pensamento corrente destacava que o fenômeno da fome era algo natural e impossível de ser revertido. Por isso, Josué de Castro (1946, p. 55) colocou na introdução do livro: "Interesses e preconceitos de ordem moral e de ordem política e econômica de nossa chamada civilização ocidental tornaram a fome um tema proibido, ou pelo menos pouco aconselhável de ser abordado".

Este autor afirma que para o estudo da alimentação, devido a sua complexidade, é necessário abordar diversos aspectos da realidade e que "o único método eficaz para essa análise é o método geográfico" (CASTRO, 2006, p. 72). Neste sentido, o autor entende o método geográfico como um método de síntese dos diversos conhecimentos, sejam eles naturais ou humanos, que ocorrem sobre a superfície da Terra. A base da definição do método está nos quatro "princípios geográficos", que podem ser notados em toda sua obra.

O primeiro princípio seria o da localização, extensão e delimitação, que determina que o geógrafo deve sempre localizar e delimitar a ocorrência dos fenômenos que ocorrem sobre a superfície da Terra. O segundo, o da coordenação ou correlação, no qual o entendimento de cada fenômeno nunca se dá de 
modo isolado, mas sempre leva em consideração outros fenômenos ocorridos em outras partes do globo terrestre. 0 terceiro, o da conexidade que aponta para a conexão dada pelo meio aos fenômenos impondo uma unidade terrestre. 0 quarto, e último, o da causalidade que estabelece que os geógrafos ao examinar qualquer fenômeno, devem atentar para suas causas e efeitos. A opção pelo método geográfico possibilitou ao autor uma análise mais ampla sobre as necessidades fundamentais das populações.

Com base nesse mosaico da vida brasileira da década de 1940, é necessário ressaltar que a temática da fome tem tanto um significado científico de cunho político, como também é um elemento potente na realização da crítica ou denúncia das relações sociais existentes no país e também no mundo. A fome é um fenômeno de ordem universal. Mas, as grandes penúrias devastadoras, aquelas que atraem a atenção dos homens, flagelam com mais ou menos intensidade ou frequência, conforme os países. Há regiões que são consideradas terras clássicas da fome, como é o caso, dos grandes formigueiros da Ásia Oriental e Sul-Oriental, nos quais o estado atual da técnica de produção não permite uma vitória definitiva contra as forças hostis do clima ou restaurar o desgaste dos solos (SORRE, 2003).

A complexidade do perfil nutricional dos países, marcada por uma expressiva diversidade de padrões econômicos, hábitos culturais e alimentares, além da coexistência de problemas nutricionais típicos de sociedades subdesenvolvidas e de países desenvolvidos, mostra a necessidade de conhecer a magnitude dos agravos nutricionais nas diferentes regiões (VIEIRA, ET AL., 2008).

\section{A EDUCAÇ̃̃O NUTRICIONAL BRASILEIRA}

No Brasil, o interesse pela Educação Nutricional surgiu nos anos quarenta, período em que gozou de status privilegiado e era vista como um dos pilares dos programas governamentais de proteção ao trabaIhador. Ela nasceu com a perspectiva de ser uma ala- vanca que determinaria mudanças significativas nas condições de alimentação da população trabalhadora (CASTRO; PELIANO, 1985).

A educação, cujo conceito corresponde a algo mais amplo, sempre é vista como referência, quer seja ela positiva ou negativa, ainda é tida de forma restrita por muitos que a vinculam apenas aos conhecimentos adquiridos em instituições de ensino escolar.

De acordo com Kury (2002, p. 370), o conceito de educação corresponde a:

\begin{abstract}
1. Ato ou efeito de educar. 2. Conjunto de normas pedagógicas tendentes ao desenvolvimento das faculdades psíquicas, intelectuais e morais da criança e do ser humano em geral. 3. Conhecimento e prática dos hábitos sociais; polidez, civilidade, boas maneiras. 4. Arte de adestrar animais. 5. Instrução. 6. Aperfeiçoamento. Educação infantil. A primeira etapa da educação básica (pré-escola), para crianças até seis anos de idade. E.du.ca.ção. Educacional adj. 2gên. Relativo à educação. E.du.ca.ci.o.nal. (Grifos do autor).
\end{abstract}

Segundo Nérici (1993, p. 43):

[...] educação é o processo que visa a revelar e a desenvolver as potencialidades do indivíduo em contato com as realidades, a fim de levá-lo a atuar na mesma de maneira consciente (com conhecimento), eficiente (com tecnologia) e responsável (eticamente) a fim de serem atendidas as necessidades e aspirações da criatura humana, de natureza pessoal, social transcendental.

Para Brandão (1985, p. 82), "não há uma forma única nem um único modelo de educação; a escola não é o único lugar onde acontece e talvez nem seja o melhor; o ensino escolar não é sua única prática e o professor profissional não é seu único praticante". Nesse sentido, a educação passa a ser vista como um bem social seja formal ou não, intrínseca ao legado cultural de cada nação. Ao trazer esses conceitos amplos e densos para o mundo contemporâneo, percebe-se a sua total importância, tanto que tradicionalmente inúmeros segmentos estão no foco da educação como solução para os problemas sociais, a exemplo da educação sexual, 
tecnológica, no trânsito, ambiental, dentre inúmeras outras, assim como a educação alimentar.

Entende-se então, que o conceito de educação refere-se não só às questões ligadas ao ensino escolar, ou seja, às condições para a realização e absorção da instrução e à própria instrução, que se vincula à formação intelectual do ser humano, mediante o domínio de certos níveis de conhecimentos denominados sistematizados. Além disso, liga-se diretamente aos ensinamentos familiares, o primeiro contato do ser humano após seu nascimento. Dessa forma, a educação familiar perpassa pelo desenvolvimento da personalidade, a construção do caráter, moral, ética, orientações, ideais, valores, princípios, dentre outros fatores que fazem de cada ser humano um diferencial de acordo com suas concepções de mundo e relações com o meio social.

A educação nutricional tem como conceito ser um processo educativo, no qual, por meio da união de conhecimentos e experiências do educador e do educando, vislumbra-se tornar os sujeitos autônomos e seguros para realizarem suas escolhas alimentares de modo que garantam uma alimentação saudável e prazerosa, propiciando, então, o atendimento de suas necessidades fisiológicas, psicológicas e sociais (LIMA, 2004).

Baseado nessa afirmação destaca-se, ainda, a crescente importância da educação alimentar e nutricional no contexto da promoção da saúde e da alimentação saudável, vista como uma estratégia fundamental para enfrentar os novos desafios nos campos da saúde, alimentação e nutrição. Entretanto, enfatiza-se que há poucas referências sobre o arcabouço teórico, metodológico e operacional, tanto na literatura acadêmica como nos documentos de referência que norteiam as políticas públicas no campo. Ou seja, paradoxalmente, a "educação alimentar e nutricional está em todos os lugares e, ao mesmo tempo, em lugar nenhum" (SANTOS, 2012, p. 63).
O estudo da alimentação humana, segundo Gimenes (2008), revela-se fascinante, por permitir desvendar, a partir da análise de uma prática cotidiana, valores, significados e representações que muito dizem sobre os próprios grupos sociais.

Isso se torna possível na medida em que as decisões sobre a escolha, a produção, o armazenamento, a aquisição, o preparo e o serviço de alimentos são forjadas na própria cultura que dá substrato para a organização social, sendo norteadas por fatores objetivos (limitações impostas pelas técnicas de produção e poder aquisitivo, por exemplo) e simbólicos (significados atribuídos socialmente aos alimentos que podem resultar em valorações, positivas ou negativas, ou ainda proibições alimentares). Marcadas pelos contextos socioeconômicos e tecnológicos nos quais se dão, tais determinações constituem - muito mais do que o exercício da preferência individual - um exercício do habitus (BOURDIEU, 1983) do grupo e uma forma de reprodução, na microesfera cotidiana, dos condicionantes organizadores das sociedades.

A Educação Nutricional distanciou-se de suas raízes sociais e antropológicas nas décadas de 1960 e 1970, no âmbito internacional. A sociologia cedeu lugar à medicina, como mentora dos programas de Educação Nutricional, e o critério de êxito, inspirado nas concepções behavioristas de educação passou a ser exclusivamente a mudança do comportamento observável (BOOG, 2004). Nos anos que se seguiram, a educação nutricional, principalmente em meados de 1980 e 1990, era vista apenas como prática domesticadora, "comer o que se quer, na hora que se quer e como quiser". Forma segundo a autora de liberdade de expressão.

Com base nos resultados da Pesquisa Nacional sobre Saúde e Nutrição realizada pelo Ministério da Saúde, em comparação com os resultados da Pesquisa de Orçamento Familiar, realizada pelo Instituto Brasileiro de Geografia e Estatística, publicadas no inicio dos anos 1990, apontavam para o expressivo aumento na prevalência de obesidade, principalmente entre 
mulheres de baixa renda, havendo o declínio do consumo de frutas e vegetais, e o aumento do colesterol pelo consumo de gorduras. Essas conclusões foram o marco para a retomada da importância da educação nutricional - tendo foco no nutriente e não apenas no alimento, associando-os ao aspecto social.

O filosofo Edgar Morim (2004, p. 36) reforça essa ligação entre o biológico e o cultural:

O que há de mais biológico - o sexo, o nascimento, a morte - é também o que há de mais impregnado de cultura. Nossas atividades biológicas mais elementares - comer, beber, defecar - estão estreitamente ligadas a normas, proibições, símbolos, mitos, ritos, ou seja, ao que há de mais especificamente cultural; nossas atividades mais culturais - falar, cantar, dançar, amar, meditar - põe em movimento nossos corpos, nossos órgãos; portanto, o cérebro.

Os agravos à saúde e epidemiologia da obesidade ilustram, segundo Lamounie (2007), a importância e o impacto da doença, no âmbito individual e coletivo, dentre os quais, os custos alarmantes de cerca 1,5 bithão de reais por ano com internações hospitalares, consultas médicas e medicamentos. Desse valor, 600 milhões são provenientes do governo via Sistema Único de Saúde (SUS), e representam 12\% do orçamento gasto com todas as outras doenças.

A obesidade é um fenômeno que tem sido observado em praticamente todas as faixas etárias da população em vários países no mundo. Sua prevalência cresceu nos últimos anos e constitui um dos mais significativos problemas nutricionais da atualidade, devido, principalmente, às suas graves consequências biopsicossociais. Antes, mais comum entre adultos, já atinge, também, crianças e adolescentes de forma preocupante.

Outras doenças ainda são relacionadas à obesidade: dislipidemias, diabetes, hipertensão arterial, doenças respiratórias do tipo apneia do sono, litíase biliar, distúrbios dermatológicos, distúrbios alimentares, dentre outros. Segundo dados do Ministério da Saúde (2013), na pesquisa da Vigilância de Fatores de Risco e
Proteção para Doenças Crônicas por Inquérito Telefônico (Vigitel), no ano de 2012 mostra que $51 \%$ da população (acima de 18 anos) está acima do peso ideal e $14,8 \%$ da população brasileira está obesa, sendo Macapá, Porto Alegre, Natal, Fortaleza e Campo Grande, as capitais com maior índice de obesidade do país.

\section{EDUCAÇÃO NUTRICIONAL NA PRÁTICA}

A prática da educação nutricional, na atualidade, não se concebe mais de forma tradicional, segundo Turano (1999), que consistia na transmissão de conceitos de nutrição para a população, de forma homogênea, com palestras cujos conteúdos limitavam-se aos aspectos biológicos da alimentação, destacando o efeito dos nutrientes no organismo. Embora seja uma informação importante, não considera os aspectos regionais e as desigualdades sociais que comprometem o acesso da população a uma alimentação adequada (FERREIRA, 2007).

O conceito de Maciel (2004, p. 26) resume e afirma a abrangência da educação nutricional na atualidade:

\begin{abstract}
Alimentação refere-se a um conjunto de substâncias que uma pessoa ou grupo costuma ingerir, implicando a produção e o consumo, técnicas e formas de aprovisionamento, de transformação e de ingestão de alimentos. Deste modo, alimentação vai além do biológico, relacionando com o social e o cultural.
\end{abstract}

A educação é inerente à vida. O ser humano aprende e se desenvolve ao longo de sua existência no esforço por responder aos desafios diários. A educação acontece nesse cotidiano social e também por intermédio de ações de instrução e ensino planejadas por pessoas capacitadas para tal. Assim, como não se faz educação musical, artística ou moral em cursinhos de cinco dias, não há nenhuma fórmula mágica para conseguir que as pessoas passem a comer melhor de um dia para outro. Isto não justifica, porém, desconsiderar essa importante ação em prol da promoção da saúde (BOOG, 2004). 
Na perspectiva de Pierre Bourdieu (1998), apresentado no livro 0 poder simbólico, a origem de um campo de saber, e neste caso o ensino/aprendizagem, refere-se ao movimento inicial de sua constituição como área de conhecimento ou disciplina acadêmica, ao desenvolvimento de estratégias para fixar suas bases, em sua especificidade, estabelecer limites, arcabouço teórico-metodológico e aplicabilidade. Em geral, representa um momento de ruptura com modelos anteriores de análise e interpretação de fenômenos e/ ou problemas aos quais se refere. Desencadeiam-se ações estratégicas com as finalidades de depuração, legitimação social e estabelecimento de estruturas constitutivas do campo (BEZERRA, 2012).

Os aspectos fisiológicos e psicológicos são, segundo Santos (2007), os que impulsionam a conduta do ser humano. Quando tentamos entender as necessidades básicas de cada ser humano e como elas são saciadas, devemos compreender que estas fazem parte da interação complexa de mecanismos fisiológicos e processos psicológicos em cada um.

Do ponto de vista teórico-metodológico, a educação alimentar e nutricional está direcionada nos documentos para assumir uma perspectiva da educação popular cunhada no pensamento de Paulo Freire, com ênfase na dialogicidade e na autonomia do sujeito. Nesta direção, ainda se mesclam algumas contribuições da pedagogia construtivista. Assim, os discursos recorrem ao enfoque da problematização e contrapõem aos métodos tradicionais baseados nas técnicas expositivas, a fim de promover uma prática reflexiva dos sujeitos sobre si e sobre as questões pertinentes às suas práticas alimentares (SANTOS, 2012).

\section{CONSIDERACOÕES FINAIS}

Um dos direitos que compõem a Declaração Universal dos Direitos Humanos, de 1948, é o Direito Humano à Alimentação Adequada (DHAA). É um direito inerente a todas as pessoas de ter acesso regular, permanente e irrestrito, quer diretamente ou por meio de aquisições financeiras, a alimentos seguros e saudáveis e em quantidade e qualidade adequadas e suficientes, correspondentes às tradições culturais do seu povo, que garantam uma vida livre do medo, digna e plena nas dimensões física e mental, individual e coletiva.

De acordo com a Organização das Nações Unidas para Alimentação e a Agricultura (FAO), a segurança alimentar concebe que todas as pessoas, em todos os momentos de suas vidas, possam ter acesso físico, social e econômico a uma alimentação regular, segura e saudável.

A industrialização e a urbanização crescentes implantaram novas rotinas e hábitos na alimentação e por meio desta, também, é possível conhecer alguns dos principais hábitos culturais de um povo. Além disso, a globalização gera mudanças substanciais na cultura e na alimentação das pessoas e, consequentemente, nas condições de saúde. Há uma crescente oferta de alimentos industrializados (muito ricos em gorduras, açúcares e sódio) e caloricamente densos e baratos (o que afeta, em especial, as famílias de baixa renda). Necessita-se mensurar constantemente o impacto que os hábitos de alimentação inadequados podem causar a uma população (RIGHI, 2011).

As transformações sociais, segundo esse mesmo autor, culturais e econômicas produzidas pela sociedade capitalista, no último século, refletem o modo de vida da população. Tais mudanças modulam seu acesso às condições de vida mais favoráveis à saúde e, portanto, repercutem diretamente nos padrões de adoecimento. No início do século XX, os males que afligiam a população eram as epidemias causadas por doenças transmissíveis e algumas ainda não foram debeladas, como a dengue, a tuberculose, a malária, dentre outras. Já no século XXI, ocorreram mudanças no perfil epidemiológico das doenças e, hoje, disseminam-se as doenças crônicas não transmissíveis.

A noção de qualidade de vida transita, portanto, em um campo semântico polissêmico: de um lado, 
encontra-se relacionada ao modo de vida, suas condições e estilos; de outro, inclui ideias sobre o desenvolvimento sustentável e sobre os diretos humanos e sociais. Estas noções se unem em uma resultante social de construção coletiva dos padrões de conforto e tolerância que determinada sociedade estabelece como referência (PIMENTA ET AL., 2008).

Desta forma, igualmente, os estudos das necessidades básicas devem levar em conta, de acordo com Maturana (2004), os processos psicológicos construídos em cada indivíduo ao longo de sua existência, bem como a cognição como processo do conhecimento. Assim, as características pessoais, a dinâmica do aprender e os fenômenos biológicos fundamentam e envolvem todas as dimensões do ser humano. Em total integração do corpo e do espírito, e do ser com o fazer. Quando isso não ocorre, se produz alienação e perda do sentido social e individual no viver em cada ser humano.

\section{REFERÊNCIAS}

BRASIL. Ministério da Saúde. Secretaria de Atenção à Saúde. Departamento de Atenção Básica. Política Nacional de Atenção Básica - 4.ed. - Brasília: Ministério da Saúde, 2007. 68p. - (Série E. Legislação de Saúde, Série Pactos pela Saúde 2006; v.4).

BRASIL. Ministério da Saúde. Secretaria de Vigilância em Saúde. Secretaria de Atenção à Saúde. Política Nacional de Promoção da Saúde - 2.ed. - Brasília: Ministério da Saúde, 2007. 56p. - (Série B. Textos Básicos de Saúde; Série Pactos pela Saúde 2006, v.7).

BRASIL. Ministério da Saúde. Secretaria de Vigilância à Saúde. Secretaria de Atenção à Saúde. Diretrizes e recomendações para o cuidado integral de doenças crônicas não-transmissíveis: promoção da saúde, vigilância, prevenção e assistência. Brasília: Ministério da Saúde, 2008. 72p. (Série B. Textos Básicos de Atenção à Saúde; Série Pactos pela Saúde 2006, v.8).
BRASIL. Ministério da Saúde. Secretaria de Vigilância em Saúde. Departamento de Vigilância de Doenças e Agravos não Transmissíveis e Promoção de Saúde. Vigitel Brasil 2012: vigilância de fatores de risco e proteção para doenças crônicas por inquérito telefônico / Ministério da Saúde, Secretaria de Vigilância em Saúde, Departamento de Vigilância de Doenças e Agravos não Transmissíveis e Promoção de Saúde. Brasília: Ministério da Saúde, 2013.

BEZERRA, J. A. B. Educação alimentar e a constituição de trabalhadores fortes, robustos e produtivos: análise da produção científica em nutrição no Brasil, 19341941. Hist. cienc. Saúde. Manguinhos, v.19, n.1 Rio de Janeiro, jan./mar. 2012.

BO0G, M. C. F. Educação nutricional: Por que e para quê? Jornal da UNICAMP, Campinas, 2004.

BOURDIEU, P. Gostos de classe e estilos de vida. In: ORTIZ, R. Sociologia. São Paulo: Ática, 1983.

BOURDIEU, P. 0 poder simbólico. Trad. Fernando Tomaz. Rio de Janeiro: Bertrand Brasil, 1998.

BRANDÃO, C. R. 0 que é educação. São Paulo: Abril Cultura; Brasiliense, 1985

CASTRO, J. Geografia da fome. 6.ed. Rio de Janeiro: Civilização Brasileira, 2006.

CASTRO, C.M., PELIANO, A.M. Novos alimentos, velhos hábitos e o espaço para ações educativas. In: CASTRO, C. M., COIMBRA, M. 0 problema alimentar no Brasil. São Paulo: ALMED,1985. p.195-213.

FERREIRA, V.A.; MAGALHÃES, R. Nutrição e promoção da saúde: perspectivas atuais. Cad. Saúde Publica, 23 (7): 1674-1681, 2007.

GIMENES, M.H.S.G. Cozinhando a tradição: festa, cultura e história no litoral paranaense. 2008. 405f. Tese (Doutorado) - Universidade Federal do Paraná, Curitiba, 2008. 
LAMOUNIE, J. A.; PARIZZI, M. R. Resenha Obesidade e Saúde Pública. Anjos LA. Cad. Saúde Pública, v.23, n.6, Rio de Janeiro: Fiocruz; 2006. 100p.

LIMA, K. A. Análise do processo de construção do conhecimento dietoterápico de pacientes diabéticos atendidos no programa saúde da família do município de Araras. 2004. 271f. Dissertação (Mestrado) - Faculdade de Ciências Farmacêuticas, Universidade Estadual Paulista, Araraquara, 2004.

KURY, G. Minidicionário da língua portuguesa. São Paulo: FTD, 2002.

MACHADO NETO, A. L. A estrutura social da república das letras. São Paulo: EDUSP/Grijalbo, 1973.

MACIEL, M. E. Uma cozinha brasileira. Estudos históricos, n.33, Rio de Janeiro, 2004. p.25-39.

MATURANA, H.R. Del ser al hacer. Los Orígenes de La biologia del conocer. Santiago: J C Sáez, 2004.

MORIN, E. A Cabeça bem feita. São Paulo: Bertrand Brasil, 2004.

NÉRICI, I. G. Didática do ensino superior. São Paulo: Ibrasa, 1993.

OMS. Organización Mundial de la Salud. Dieta, nutrición y prevención de enfermidades no-transmisibles. Genebra (OMS - Serie de Informes Técnicos, 797), 1986.

ONU - Organização das Nações Unidas. Declaração universal dos direitos humanos. Nova lorque: ONU, 1948. Disponível em: <http://www.unhchr.ch/udhr/ lang/por.htm>. Acesso em: 8 abr. 2015.

ORGANIZAÇÃO DAS NAÇÕES UNIDAS PARA A ALIMENTAÇÃO E AGRICULTURA (FAO). Quase 870 milhões de pessoas no mundo estão subnutridas - novo relató- rio sobre a fome. Disponível em. <https://www.fao.org. br/q870mpmesnrsf.asp>. Acesso em: 12 dez. 2014.

PASSIANI, Enio. Na trilha do Jeca: Monteiro Lobato, o público leitor e a formação do campo literário no Brasil. Sociologias [on-line], n.7, 2002, p.254-270. ISSN 1517-4522.

PIMENTA, F. A. P. et al. Avaliação da qualidade de vida de aposentados com a utilização do questionário SF36. Revista. Assoc. Med Bras. v.54, n.1, 2008. p.55-60.

PINHEIRO, Anelise Rizzolo de Oliveira, et al. Uma Abordagem epidemiológica da obesidade. Revista Nutrição, v.17 n.4, Campinas, 2004.

RIGHI, A. S. Desenvolvimento das políticas públicas: Saúde, Educação e Serviço Social - convergência necessária. Revista de Graduação da PUCRS, v.4, n.2, 2011

SANTOS, B. S. et al. Vida adulta, processos motivacionais e diversidade. Educação, n.1(61), Porto Alegre: 2007. p.149-164.

SANTOS, L. A. S. O fazer educação alimentar e nutricional: algumas contribuições para reflexão. Ciência e saúde coletiva, v.17, n.2, Rio de Janeiro, fev. 2012.

SORRE, M. Cadernos de Ciência \& Tecnologia, Brasília, v.20, n.2, maio/ago. 2003. p.367-371.

TURANO, W. A. C. C. A. Educação nutricional. In: Gouveia ELC. Nutrição, comunidade e saúde. Rio de Janeiro: Revinter, 1999

VIEIRA, M. F. A.; et al. Estado nutricional de escolares de 1a a 4 a séries do Ensino Fundamental das escolas urbanas da cidade de Pelotas, Rio Grande do Sul, Brasil. Caderno de Saúde Pública, 24(7):1667-1674, Rio de Janeiro, jul. 2008. 
1. Coordenador do curso de Nutrição e professor da Universidade Tiradentes, doutorando em Educação da Pontifícia Universidade Católica do Rio Grande do Sul, mestre em Saúde e Ambiente pela Universidade Tiradentes, graduado em Nutrição. E-mail: nutricao@unit.br

2. Professora e coordenadora do Grupo de Pesquisa "Processos Motivacionais em Contextos Educativos" da FACED/PUCRS, coordenadora do Curso de Especialização em Psicopedagogia e bolsista de Produtividade em Pesquisa - PQ/CNPq. É doutora em Psicologia Evolutiva e da Educação - Universidad de Barcelona. Possui Pós-doutorado no College of Education, The University of Texas at Autin, EUA. É graduada em Pedagogia pela UFRGS. E-mail: bettina@pucrs.br

3. Professora do curso de Psicologia da Universidade Tiradentes, doutoranda em Educação pela Pontifícia Universidade Católica do Rio Grande do Sul, mestre em Educação pela Universidade Tiradentes, graduada em Psicologia. Líder do grupo de pesquisa Educação, Cultura e Desenvolvimento Aceito em: 20 de Julho de 2015 